\title{
ЭЛЕКТРОННЫЕ РЕСУРСЫ. ЭЛЕКТРОННЫЕ БИБЛИОТЕКИ
}

УДК 001.4

\author{
Н. И. Колкова, И. Л. Скипор \\ Кемеровский государственный институт культуры
}

\author{
Терминосистема предметной области \\ «электронные информационные ресурсы»: \\ взгляд с позиций теории и практики
}

\begin{abstract}
Рассмотрены объективные предпосылки и проблемы формирования терминосистемы предметной области «электронные информационные ресурсы». Дана оценка лексики, используемой при отражении электронных информационных ресурсов в составе контента сайтов центральных библиотек субъектов Российской Федерации. Приведены результаты анализа межгосударственных и национальных стандартов РФ, регламентирующих терминологию в области электронных информационных ресурсов. Выявлены виды электронных информационных ресурсов в составе действующих стандартов. Сделан вывод о том, что терминологический аппарат, характеризующий отдельные виды этих ресурсов, отражен как в отдельных стандартах, так и в различных системах стандартов, нередко несогласованных между собой.
\end{abstract}

Ключевые слова: терминосистема, стандартизация терминологии, электронные информационные ресурсы.

UDC 001.4

\section{Nadezhda Kolkova and Inna Skipor \\ Kemerovo State Institute of Culture, Kemerovo, Russia}

\section{Term-system of the subject area of digital resources: From the viewpoint of theory and practice}

Objective preconditions and problems of forming term-system of the subject area of digital information resources are examined. The vocabulary used for describing digital information resources within the contents of the www-sites of RF subjects' central libraries is assessed. The findings of the analysis of international and RF national terminology standards in the area of digital information resources are introduced.

Keywords: term-system, terminology standardization, digital information resources. 
In accordance with the state standard GOST 7.0-99 "SIBID. Information and library activities, bibliography. Terms and definitions" the terminosystem is an organized set of terms in the special language of a particular field of knowledge. The authors studied 55 websites of central regional libraries of the Russian Federation, namely Far Eastern, Crimean, Volga basin, North Western, Siberian, Ural, Central, and Southern federal districts; all these libraries had collections of electronic resources. The goal was to outline and to evaluate the lexical parameters of description of the electronic resources. Some typical errors are analyzed, in particular, wrong classification, incorrect notations, lack of unification in notations, lack of reference information, wrong understanding and usage of the "type vs kind" relations (here e.g. "database vs electronic catalog" relation), and so on. Pretty often one could find wrong attribution of events (e.g. "collection" instead of "exhibition"). Weakness of existing base of normalized definitions, multitude of non coherent definitions of "electronic document", "data base", "internet resource", "website", etc., and lack of state standards on this subject is discussed. Future additions to normative definitions (electronic resource, digital resource, electronic document, electronic collection, electronic publication, electronic book, data base, electronic library, electronic journal, package of documents, and so on) given in standards to be adopted in 2016 (GOST 33249-2015, GOST R 7.0.94-2015 SIBID), would facilitate development of innovative library technologies. The discrepancies in definitions are analyzed. The authors propose to develop multidimensional classification system with the facet formulas for definite kind of resource, to introduce the unified terminology with a full set of attributes, to continue the updating of normative documents, to create a thesaurus, and to publish a set of methodological recommendations.

\section{Объективные предпосылки упорядочения терминологии предметной области «электронные информационные ресурсы»}

Одним из проявлений инновационной деятельности библиотечноинформационных учреждений стало развитие диверсифицированного библиотечно-информационного сервиса, ориентированного на использование качественно новой информационной базы, включающей как аналоговые, так и электронные информационные ресурсы (ЭИР). Использование ЭИР открывает особые перспективы для повышения эффективности обслуживания пользователей библиотечно-информационных учреждений в режиме удалённого доступа.

\footnotetext{
В данном случае термин «удалённый доступ», по мнению членов редколлегии нашего журнала, некорректен; более верным (подходящим) было бы одно из следующих определений: дистанционный, сетевой, отдалённый. - Ред.
} 
Предоставление конечным пользователям возможности самостоятельной работы в удалённом режиме обязывает обеспечить прозрачность размещённых в открытом информационном пространстве ЭИР, благодаря которой они могли бы быть не только легко выявлены, но и легко идентифицированы. Реализация этого условия эффективного функционирования ЭИР выдвигает требования терминологического характера, которые связаны с формированием терминосистемы, соответствующей их специфическим особенностям. С учётом интересов как разработчиков, так и конечных пользователей, в первую очередь, она должна устанавливать видовой состав ЭИР.

\section{Теоретическое обоснование исследования}

В теории терминоведения отмечено: «Важная особенность терминов состоит в том, что они - члены определённой строгой системы. Систематичность терминов, строгая зависимость единиц внутри терминологий - вот главная характеристическая черта этого разряда слов. В каждой определённой области науки и техники терминология представляет собой исчислимую и замкнутую систему» [1. C. 263]. Поэтому принципиально важно рассматривать используемый в любой предметной области понятийнотерминологический аппарат как систему, где каждый элемент, выполняя свою специфическую функцию, должен иметь конкретное, установленное с позиций системного подхода обозначение. При этом, как отмечает Д. С. Лотте, «научно определить какое-либо понятие можно, лишь точно установив, какое место данное понятие должно занимать среди других понятий, и поэтому вопросы классификации также не могут уйти из поля зрения специалистов, работающих над терминологией» [2. С. 113].

В соответствии с ГОСТом 7.0-99 «СИБИД. Информационно-библиотечная деятельность, библиография. Термины и определения», терминосистема - организованная совокупность терминов в специальном языке определённой области знания [3. С. 11]. Важнейшим элементом терминосистемы является термин - слово или словосочетание, являющееся точным обозначением определённого понятия какой-либо области знания [Там же]. Термин неразрывно связан с обозначаемым им понятием, под которым понимается «форма мышления, отражающая существенные свойства, связи и отношения предметов и явлений» [Там же. С. 10].

Как и в любой другой предметной области, семантические отношения между терминами, обозначающими виды ЭИР, как элементы терминосистемы должны иметь логический характер, определяемый иерархическими (отношениями «род - вид» и «часть - целое») и ассоциативными отношениями. При этом построение словосочетаний, обозначающих виды ЭИР, должно подчиняться единым для терминологических систем требованиям и определяться соответствующими семантическими моделями. При таком 
подходе, поддерживаемом всеми генераторами электронных информационных ресурсов и повсеместно используемом в библиотечно-информационной практике, ориентация конечных пользователей библиотечно-информационных учреждений как собственных, так и заимствованных ими ЭИР могла бы быть значительно более продуктивной, а их использование - не только комфортным, но и эффективным.

Нарушение этих требований порождает серьёзные барьеры на пути конечного пользователя к искомому ЭИР. Доказательства тому были получены в ходе проведённого в 2015 г. на кафедре технологии автоматизированной обработки информации (ТАОИ) Кемеровского государственного института культуры (КемГИК) исследования ЭИР, представленных на официальных сайтах библиотек Российской Федерации.

\section{Содержание и результаты исследования}

Цель исследования - получение данных, характеризующих состояние понятийно-терминологического аппарата, используемого в практической деятельности по созданию и использованию ЭИР в масштабах России. Достижение поставленной цели обеспечивалось посредством формирования репрезентативной выборочной совокупности объектов исследования, в которую вошли 55 сайтов центральных библиотек (ЦБ) субъектов РФ (областей, краёв), зарегистрированных на информационно-справочном портале Library.ru (http://www.library.ru/3/biblionet/) и доступных на момент исследования.

В качестве сформированных кластеров выборки выступили группы ЦБ субъектов РФ, входящих в состав восьми федеральных округов Российской Федерации: Дальневосточного, Крымского, Приволжского, Северо-Западного, Сибирского, Уральского, Центрального, Южного. Такой подход к формированию выборки объектов исследования позволил получить сведения, которые могут быть интерпретированы как типичные для ЦБ субъектов РФ.

Задачами исследования являлись: выявление и оценка лексики, характеризующей состав ЭИР, представленных на сайтах ЦБ субъектов РФ. Результаты анализа контента этих сайтов показали, что ЭИР в той или иной степени присутствуют во всех библиотеках - объектах исследования. На сайтах ЦБ в числе ЭИР отражены как заимствованные (приобретённые путём покупки или полученные безвозмездно), так и самостоятельно генерируемые ЭИР. При этом преимущественное положение среди ЭИР собственной генерации занимают ресурсы, представленные на сайтах ЦБ субъектов РФ в блоке краеведческой информации.

При проведении анализа лексики, задействованной для отражения практических достижений ЦБ субъектов РФ в сфере генерации и использования ЭИР, учитывались важнейшие признаки терминосистем, прежде всего то, что «терминология предметной области не должна быть случайным 
набором терминов» [4. С. 22]. При этом терминосистема предметной области «электронные информационные ресурсы» априори обязана представлять единство всех её элементов и в то же время отражать всю совокупность признаков, определяемых используемыми в данной системе классификационными схемами.

В результате оценки лексики с позиций важнейших признаков терминосистем выявлен ряд разносторонних несоответствий, исходя из сущности которых составлен перечень логических и формальных ошибок, допускаемых практиками при номинировании ЭИР, представляемых конечным пользователям на официальных сайтах ЦБ субъектов РФ (табл. 1).

Таблица 1

\section{Состав ошибок в представлении конечным пользователям ЭИР на официальных сайтах ЦБ субъектов Российской Федерации}

\begin{tabular}{|c|c|}
\hline Вид ошибки & Примеры \\
\hline \multicolumn{2}{|l|}{ 1. Нарушение правил классификации ЭИР } \\
\hline $\begin{array}{l}\text { - Нарушение соотношения объёмов } \\
\text { понятий, находящихся в отношениях } \\
\text { иерархии, в частности объединение } \\
\text { родовых и видовых понятий через } \\
\text { союз «и» }\end{array}$ & $\begin{array}{l}\text { • «Электронные каталоги и базы данных»; } \\
\text { • «Электронные краеведческие каталоги и базы } \\
\text { данных»; } \\
\text { • «Базы данных и электронный каталог»; } \\
\text { • «Базы данных и электронный краеведческий } \\
\text { каталог» }\end{array}$ \\
\hline $\begin{array}{l}\text { - Перечисление в одном ряду ЭИР, } \\
\text { относящихся к родовым, видовым и } \\
\text { единичным понятиям, без использо- } \\
\text { вания какой-либо их группировки }\end{array}$ & $\begin{array}{l}\text { Базы данных «Персоналии», «Организации», «Гео- } \\
\text { графические названия»; полнотекстовые БД }\end{array}$ \\
\hline $\begin{array}{l}\text { - Перечисление в одном ряду видов } \\
\text { ЭИР, выделенных по разным класси- } \\
\text { фикационным признакам }\end{array}$ & $\begin{array}{l}\text { - Универсальная база данных; } \\
\text { • Библиографическая база данных }\end{array}$ \\
\hline $\begin{array}{l}\text { - Неправомерное отнесение конкретно- } \\
\text { го ЭИР к определённому виду ЭИР }\end{array}$ & $\begin{array}{l}\text { Электронные коллекции: } \\
\text { • полнотекстовая БД «История...»; } \\
\text { • полнотекстовая БД «Солдат войны не выбира- } \\
\text { ет...»; } \\
\text { • виртуальные выставки; } \\
\text { • } \text { электронная библиотека диссертаций; } \\
\text { • электронный архив }\end{array}$ \\
\hline $\begin{array}{l}\text { - Перечисление в одном ряду достаточ- } \\
\text { но сложных по программной реализа- } \\
\text { ции ЭИР (таких как базы данных, } \\
\text { электронные коллекции документов и } \\
\text { др.) и списков электронных докумен- } \\
\text { тов в формате Word }\end{array}$ & $\begin{array}{l}\text { • Базы данных; } \\
\text { • Электронные коллекции документов; } \\
\text { • Списки электронных книг краеведческой тема- } \\
\text { тики, посвящённых конкретной персоне или } \\
\text { конкретному событию и т.д. }\end{array}$ \\
\hline
\end{tabular}


Продолжение таблицы 1

\begin{tabular}{|c|c|}
\hline Вид ошибки & Примеры \\
\hline \multicolumn{2}{|l|}{ 2. Некорректное обозначение видов ЭИР } \\
\hline $\begin{array}{l}\text { Пропуск принципиально важного } \\
\text { элемента словосочетания в обозначе- } \\
\text { нии вида информационного ресурса, } \\
\text { приводящий к сложности его иденти- } \\
\text { фикации в качестве ЭИР либо к мно- } \\
\text { гозначности трактовки ЭИР } \\
\end{array}$ & $\begin{array}{l}\text { - Краеведческий каталог; } \\
\text { - Каталог периодических изданий; } \\
\text { - Полнотекстовая коллекция; } \\
\text { - База данных }\end{array}$ \\
\hline $\begin{array}{l}\text { - Наличие лишнего элемента (логиче- } \\
\text { ского звена) в обозначении вида ЭИР, } \\
\text { что порождает его непрофессиональ- } \\
\text { ную трактовку }\end{array}$ & $\begin{array}{l}\text { - Полнотекстовая электронная коллекция доку- } \\
\text { ментов; } \\
\text { • Электронная база «Ноты»; } \\
\text { • Электронная база «Музыкальные произведе- } \\
\text { ния»; } \\
\text { - Электронная база «Песни» }\end{array}$ \\
\hline \multicolumn{2}{|c|}{ 3. Отсутствие унификации при указании вида и наименования ЭИР } \\
\hline $\begin{array}{l}\text { - Указание вида ЭИР перед его назва- } \\
\text { нием }\end{array}$ & • Электронная коллекция «Весь ...» \\
\hline $\begin{array}{l}\text { - Указание вида ЭИР после его назва- } \\
\text { ния }\end{array}$ & $\begin{array}{l}\text { - «Выдающиеся деятели культуры ... области»: } \\
\text { электронный энциклопедический ресурс }\end{array}$ \\
\hline $\begin{array}{l}\text { - Указание на вид ЭИР через дефис или } \\
\text { двоеточие }\end{array}$ & $\begin{array}{l}\text { - } \text { «Памятники ...»: полнотекстовый электронный } \\
\text { ресурс - БД }\end{array}$ \\
\hline $\begin{array}{l}\text { - Перечисление в одном ряду ЭИР, } \\
\text { имеющих обозначение вида, и ЭИР, } \\
\text { где сведения о виде отсутствуют }\end{array}$ & $\begin{array}{l}\text { Электронные ресурсы: } \\
\text { • библиотечный хронограф; } \\
\text { • электронные каталоги }\end{array}$ \\
\hline $\begin{array}{l}\text { - Отсутствие указания вида каждого } \\
\text { конкретного ЭИР, в результате чего в } \\
\text { одном ряду перечисляются ЭИР, от- } \\
\text { носящиеся к различным видам }\end{array}$ & $\begin{array}{l}\text { • Электронный каталог; } \\
\text { • «Литература о ... области»; } \\
\text { • «Кто есть кто в библиотечном мире ...»; } \\
\text { • «Улицы носят их имена» и т.д. } \\
\end{array}$ \\
\hline \multicolumn{2}{|c|}{ 4. Отсутствие сведений об ЭИР, выполняющих справочную функцию } \\
\hline \multicolumn{2}{|c|}{\begin{tabular}{ll|l} 
• Отсутствие паспортных данных ЭИР & \\
\end{tabular}} \\
\hline $\begin{array}{l}\text { - Отсутствие сведений о возможности } \\
\text { удалённого доступа к ЭИР или рас- } \\
\text { пространение этих сведений только } \\
\text { на заимствованные ЭИР }\end{array}$ & \\
\hline
\end{tabular}

Как видно из табл. 1, круг ошибок в составе лексики, характеризующей виды ЭИР на официальных сайтах ЦБ субъектов РФ, достаточно широк. В первую очередь, обращает на себя внимание игнорирование практикой роли родо-видовых отношений, имеющих существенное значение при формировании единого подхода к упорядочению лексики любой предметной области. Так, при переходе от традиционных к электронным информа- 
ционным ресурсам с позиций пользователей ЭИР логична следующая цепь родо-видовых отношений: родовое понятие - «информационные ресурсы»; видовые понятия - «традиционные (аналоговые) информационные ресурсы», «электронные информационные ресурсы».

В свою очередь, словосочетание «электронные информационные ресурсы» может рассматриваться как родовое понятие, для которого в качестве видовых может быть рассмотрен широкий набор их видов, включая локальные и удалённые ЭИР. Понятия «локальные ЭИР» и «удалённые ЭИР» также на более низком уровне могут рассматриваться как родовые. При этом в составе удалённых ЭИР в зависимости от происхождения могут быть выделены интернет-ресурсы, включающие веб-ресурсы, и т.д.

С этой точки зрения типичное для современной практики объединение через союз «и» понятий «базы данных» и «электронные каталоги» следует считать противоречащим системному подходу к формированию терминосистемы предметной области «электронные информационные ресурсы». По существу эти понятия связаны между собой отношением «род - вид», в которых понятие «база данных» является родовым, а любые электронные каталоги в силу их сущностных характеристик при этом надлежит рассматривать в качестве разновидности баз данных. С позиций системного подхода обозначение электронных каталогов как элемента терминосистемы «электронные информационные ресурсы» требует построения словосочетаний типа: библиографическая база данных «Электронный каталог»; библиографическая база данных «Электронный краеведческий каталог» и т.д.

Весьма распространённый вариант ошибок - пропуски важных элементов словосочетания в обозначении ЭИР в целом и их видов. Прежде всего, это относится к использованию усечённого словосочетания «электронные ресурсы» вместо более полного и точного - «электронные информационные ресурсы». Удаление его средней части, на наш взгляд, приводит к потере важного признака, указывающего на то, что ЭИР являются одной из разновидностей информационных ресурсов. Размещение информационных ресурсов и электронных информационных ресурсов в составе различных рубрик сайтов без использования перекрёстных ссылок дезориентирует их конечных пользователей.

На официальных сайтах ЦБ субъектов РФ часто встречается такая ошибка, как неопределённость в установлении разновидности того или иного вида электронного информационного ресурса, и в основном это касается баз данных. Как известно, классификация БД может осуществляться по многим признакам, что позволяет весьма детализировано идентифицировать каждую конкретную БД. Однако чаще всего конечный пользователь лишён возможности получить необходимую информацию такого рода. На практи- 
ке вместо словосочетаний, указывающих на вид БД («полнотекстовая база данных», «реферативная база данных», «библиографическая база данных», «фактографическая база данных» и т.д.), зачастую приводится обобщённое словосочетание «база данных». Примечательно, что полные и усечённые словосочетания при обозначении вида ЭИР, а ЭИР с указанием и без указания сведений о виде конкретного ЭИР зачастую приводятся в одном ряду.

Ещё большие трудности при поиске нужных ЭИР на сайтах библиотек возникают в тех случаях, когда полностью отсутствуют сведения о виде или разновидности ЭИР. Например, в составе контента официальных сайтов ЦБ субъектов РФ достаточно часто встречается указание лишь названий конкретных ЭИР: «Герои Социалистического Труда - ...», «Литература о ... области», «Знаменательные даты ... области», «Кто есть кто в библиотечном мире ...» и т.д. Неопределённая принадлежность ЭИР к тому или иному их виду ведёт к многозначности суждений конечного пользователя о них, что нередко приводит к необходимости многошаговых действий для установления сведений, характеризующих вид конкретных ЭИР. Например, такой весьма распространённый в сфере краеведческой деятельности ЭИР, как «Знаменательные и памятные даты...», может быть представлен и в виде оцифрованного традиционного документа, и базы данных, и электронного справочника. Однако зачастую конкретизировать специфику вида такого ресурса конечному пользователю весьма непросто.

Отказ от учёта типа семантических отношений между элементами терминосистемы в сфере ЭИР зачастую является причиной неправильного отнесения на основе собственной интуиции самими владельцами официальных сайтов конкретных ЭИР к определённому их виду. Например, под названием «Коллекции» на сайтах библиотек могут приводиться сведения о виртуальных выставках. В ЭИР, отражённых в рубрике «Электронные каталоги и базы данных», могут быть сведения об электронной библиотеке диссертаций, учебно-методическом комплексе дисциплин, электронно-библиотечной системе и др.

Одно из проявлений ошибок в терминосистеме предметной области «электронные информационные ресурсы», используемой на практике, нарушение логики упорядочения (правил группировки) сведений об ЭИР. При этом в одном ряду приводятся перечни ЭИР самых различных видов без использования какой-либо их группировки. В этих перечнях можно найти как достаточно сложные по программной реализации ЭИР (базы данных, электронные коллекции документов и др.), так и ординарные списки электронных документов (например, список книг краеведческой тематики, посвящённых конкретной персоне или конкретному событию и т.д.).

Распространившийся субъективный «авторский» подход к идентификации и обозначению вида ЭИР проявляется и на уровне выбора способа 
указания вида ЭИР. В одних случаях сведения, связанные с уточнением вида ЭИР, могут быть вынесены на первый план (например, электронная коллекция «Весь ...: современное краеведение»), а в других - приведены в конце после указания названия ЭИР через дефис или двоеточие (например, «Выдающиеся деятели культуры ... области»: электронный энциклопедический ресурс»; «Памятники ...»: полнотекстовый электронный ресурс - БД). На практике допускается перечисление в одном ряду ЭИР, имеющих обозначение вида, и без него.

Всё это позволяет характеризовать используемую в настоящее время в библиотечно-информационной практике терминосистему предметной области «электронные информационные ресурсы» как имплицитную, имеющую неопределённо-расплывчатый характер. В условиях, когда приводимые на сайтах библиотек весьма неполные и неточные сведения о генерируемых или заимствованных ЭИР, как правило, не сопровождаются их паспортами, конечные пользователи оказываются в весьма затруднительном положении при решении поисковых задач различного рода.

\section{Состав и содержание нормативной базы в сфере электронных информационных ресурсов}

Проблемы практико-ориентированной терминосистемы в области ЭИР обусловливают интерес к составу и содержанию документов, составляющих нормативную базу формирования и эксплуатации ЭИР, в частности стандартов.

Результаты проведённого нами анализа фонда межгосударственных и национальных стандартов Российской Федерации свидетельствуют о том, что предметная область «электронные информационные ресурсы» представлена в них весьма ограниченно. Прежде всего следует отметить, что дефиниция понятия «электронные информационные ресурсы» не закреплена действующими стандартами, несмотря на широкое использование данного понятия в профессиональной литературе.

Подходы к определению понятия «электронные информационные ресурсы» заложены в ГОСТе 7.82-2001 «СИБИД. Библиографическая запись. Библиографическое описание электронных ресурсов. Общие требования и правила составления». Однако определение сущности ЭИР прозвучало в нём в неявном виде. Так, лишь в п. 4.1 «Объект описания» этого ГОСТа косвенно отмечается: «Объектом для составления библиографического описания являются электронные информационные ресурсы, управляемые компьютером, в том числе те, которые требуют использования периферийного устройства, подключенного к компьютеру. Электронные ресурсы представляют собой электронные данные (информацию в виде чисел, букв, символов 
или их комбинаций), электронные программы (наборы операторов или подпрограмм, обеспечивающих выполнение определённых задач, включая обработку данных) или сочетание этих видов в одном ресурсе» [5. С. 350]. Как видно из приведённого фрагмента, в стандарте в одном ряду рассматриваются понятия «электронные информационные ресурсы» и «электронные ресурсы», при этом не ясно, в каких отношениях они находятся - в отношениях тождества (синонимии) или в отношениях иерархии.

Усугубляет проблему отсутствие закреплённых нормативными документами видов ЭИР. Лишь в виде исключения из правил можно рассматривать тот факт, что в ГОСТе 7.73-96 «СИБИД. Поиск и распространение информации. Термины и определения» определены виды баз данных, в ГОСТе Р 7.0.83-2013 «СИБИД. Электронные издания. Основные виды и выходные сведения» - виды электронных изданий, в ГОСТе 7.82-2001 «СИБИД. Библиографическая запись. Библиографическое описание электронных ресурсов. Общие требования и правила составления» (исходя из задач библиографического описания) - два вида электронных ресурсов в зависимости от режима доступа: ресурсы локального и ресурсы удалённого доступа.

Выявленные в составе действующих межгосударственных и национальных стандартов Российской Федерации виды ЭИР отражены в табл. 2.

Таблица 2

Состав элементов терминосистемы предметной области «электронные информационные ресурсы» в действующих межгосударственных и национальных стандартах Российской Федерации

\begin{tabular}{|l|l|}
\hline \multicolumn{1}{|c|}{ Вид ЭИР } & \multicolumn{1}{|c|}{ Обозначение и наименование стандарта } \\
\hline $\begin{array}{l}\text { Электронный } \\
\text { документ (ЭлД) }\end{array}$ & $\begin{array}{l}\text { ГОСТ Р 52292-2004. Информационная технология. Электронный } \\
\text { обмен информацией. Термины и определения }\end{array}$ \\
\hline $\begin{array}{l}\text { Электронный } \\
\text { документ }\end{array}$ & $\begin{array}{l}\text { ГОСТ 7.83-2001 СИБИД. Электронные издания. Основные виды } \\
\text { и выходные сведения }\end{array}$ \\
\hline $\begin{array}{l}\text { Электронный } \\
\text { документ }\end{array}$ & $\begin{array}{l}\text { ГОСТ Р 7.0.83-2013 СИБИД. Электронные издания. Основные виды } \\
\text { и выходные сведения }\end{array}$ \\
\hline $\begin{array}{l}\text { Электронный } \\
\text { документ }\end{array}$ & $\begin{array}{l}\text { ГОСТ Р 7.0.8-2013 СИБИД. Делопроизводство и архивное дело. } \\
\text { Термины и определения }\end{array}$ \\
\hline $\begin{array}{l}\text { Электронный } \\
\text { документ }\end{array}$ & ГОСТ Р 52653-2006. ИКТ в образовании. Термины и определения \\
\hline $\begin{array}{l}\text { Документ } \\
\text { электронный (ДЭ) }\end{array}$ & $\begin{array}{l}\text { Р 50.1.031-2001. Рекомендации по стандартизации. Информационные } \\
\text { техногии поддержки жизненного цикла продукции. Терминологиче- } \\
\text { ский словарь. Ч.1. Стадии жизненного цикла продукции }\end{array}$ \\
\hline $\begin{array}{l}\text { Электронный } \\
\text { конструкторский } \\
\text { документ }\end{array}$ & $\begin{array}{l}\text { ГОСТ 2.001-2013. Единая система конструкторской документации. } \\
\text { Общие положения }\end{array}$ \\
\hline $\begin{array}{l}\text { Электронное } \\
\text { издание }\end{array}$ & $\begin{array}{l}\text { ГОСТ Р 7.0.83-2013 СИБИД. Электронные издания. Основные виды } \\
\text { и выходные сведения }\end{array}$ \\
\hline
\end{tabular}


Продолжение таблицы 2

\begin{tabular}{|c|c|}
\hline Вид ЭИР & Обозначение и наименование стандарта \\
\hline $\begin{array}{l}\text { Электронное } \\
\text { издание }\end{array}$ & $\begin{array}{l}\text { ГОСТ 7.83-2001. Электронные издания. Основные виды и выходные } \\
\text { сведения }\end{array}$ \\
\hline База данных (БД) & $\begin{array}{l}\text { ГОСТ 7.73-96 СИБИД. Поиск и распространение информации. } \\
\text { Термины и определения }\end{array}$ \\
\hline База данных & ГОСТ Р 52653-2006. ИКТ в образовании. Термины и определения \\
\hline $\begin{array}{l}\text { Электронный } \\
\text { образовательный } \\
\text { ресурс (ЭОР) }\end{array}$ & $\begin{array}{l}\text { ГОСТ Р 52653-2006. ИКТ в образовании. Термины и определения; } \\
\text { ГОСТ Р 53620-2009. ИКТ в образовании. Электронные } \\
\text { образовательные ресурсы. Общие положения }\end{array}$ \\
\hline $\begin{array}{l}\text { Электронный } \\
\text { учебно- } \\
\text { методический } \\
\text { комплекс (ЭУМК) }\end{array}$ & $\begin{array}{l}\text { ГОСТ Р 53620-2009. ИКТ в образовании. } \\
\text { Электронные образовательные ресурсы. Общие положения }\end{array}$ \\
\hline $\begin{array}{l}\text { Образовательный } \\
\text { Интернет-портал } \\
\text { федерального } \\
\text { уровня }\end{array}$ & $\begin{array}{l}\text { ГОСТ Р 52656-2006. ИКТ в образовании. Образовательные } \\
\text { Интернет-порталы федерального уровня. Общие требования }\end{array}$ \\
\hline Интернет-ресурс & $\begin{array}{l}\text { ГОСТ Р 52872-2012. Интернет-ресурсы. Требования доступности } \\
\text { для инвалидов по зрению }\end{array}$ \\
\hline Веб-сайт & $\begin{array}{l}\text { ГОСТ Р 52872-2012. Интернет-ресурсы. Требования доступности } \\
\text { для инвалидов по зрению }\end{array}$ \\
\hline Электронная карта & $\begin{array}{l}\text { ГОСТ Р 50828-95. Геоинформационное картографирование. } \\
\text { Пространственные данные, цифровые и электронные карты. } \\
\text { Общие требования }\end{array}$ \\
\hline
\end{tabular}

Анализ приведённых в табл. 2 сведений показывает: терминологический аппарат, характеризующий отдельные виды ЭИР в действующей отечественной нормативной базе предметной области «электронные информационные ресурсы», рассредоточен: он отражён как в отдельных стандартах, так и в различных системах стандартов, нередко несогласованных между собой. Так, дефиниции термина электронный документ отражены в таких системах стандартов, как «Информационная технология», «Система стандартов по информации, библиотечному и издательскому делу (СИБИД)», «Информационно-коммуникационные технологии в образовании», термин база данных - в стандартах СИБИД и в системе стандартов «Информационно-коммуникационные технологии в образовании». Определения терминов интернет-ресурс и веб-сайт приведены в ГОСТе Р 52872-2012 «Интернетресурсы. Требования доступности для инвалидов по зрению».

В сложившейся ситуации стремление к получению целостного представления о терминологическом аппарате, характеризующем ЭИР в разрезе действующих межгосударственных и национальных стандартов Российской Федерации, требует последовательного обращения к различным системам стандартов, в том числе не только напрямую ассоциирующимся с рассматриваемой предметной областью. 
Грядущее пополнение нормативной базы в сфере ЭИР в 2016 г., связанное с введением в действие новых стандартов в составе систем СИБИД и «Информационная технология», к сожалению, не предполагает принципиальных позитивных изменений нормативной базы предметной области «электронные информационные ресурсы». Потенциальные возможности новых национальных стандартов с позиций данной предметной области проиллюстрированы сведениями, представленными в табл. 3.

Таблица 3

\section{Состав и характеристика элементов терминосистемы предметной области «Электронные информационные ресурсы» в межгосударственных и национальных стандартах Российской Федерации, вводимых в действие в 2016 г.}

\begin{tabular}{|c|c|c|}
\hline Вид ЭИР & Дефиниция & $\begin{array}{c}\text { Обозначение и наименование } \\
\text { стандарта }\end{array}$ \\
\hline $\begin{array}{l}\text { Ресурс } \\
\text { электронный }\end{array}$ & $\begin{array}{l}\text { Любой тип ресурса, который можно пе- } \\
\text { редавать и/или получать с помощью ин- } \\
\text { формационно-технологических систем. } \\
\text { Примечание. Электронный ресурс должен } \\
\text { быть однозначно идентифицируем в при- } \\
\text { знанных системах идентификации } \\
\text { (например, ISBN, ISAN, UPC/EAN, URI) }\end{array}$ & $\begin{array}{l}\text { ГОСТ 33249-2015. Информаци- } \\
\text { онная технология. Индивидуали- } \\
\text { зированные адаптируемость и } \\
\text { доступность в обучении, образо- } \\
\text { вании и подготовке. Часть } 3 . \\
\text { Описание электронных ресурсов } \\
\text { по системе «доступ для всех» } \\
\text { (вводится в действие с } \\
01.11 .2016 \text { г.) }\end{array}$ \\
\hline $\begin{array}{l}\text { Электронный } \\
\text { ресурс }\end{array}$ & $\begin{array}{l}\text { Электронные данные (информация в виде } \\
\text { чисел, букв, символов, изображений или } \\
\text { их комбинаций) и поддерживающие их } \\
\text { программно-технологические средства }\end{array}$ & $\begin{array}{l}\text { ГОСТ Р 7.0.94-2015 СИБИД. } \\
\text { Комплектование библиотеки } \\
\text { документами. Термины и опре- } \\
\text { деления (вводится в действие с } \\
01.07 .2016 \text { г.) }\end{array}$ \\
\hline $\begin{array}{l}\text { Цифровой } \\
\text { ресурс }\end{array}$ & $\begin{array}{l}\text { Любой вид информационного ресурса, } \\
\text { представленный в виде последовательно- } \\
\text { сти дискретных (цифровых) сигналов }\end{array}$ & $\begin{array}{l}\text { ГОСТ Р 7.0.94-2015 СИБИД. } \\
\text { Комплектование библиотеки } \\
\text { документами. Термины и опре- } \\
\text { деления (вводится в действие с } \\
01.07 .2016 \text { г.) }\end{array}$ \\
\hline $\begin{array}{l}\text { Электронный } \\
\text { документ }\end{array}$ & $\begin{array}{l}\text { Документ в цифровой форме, для исполь- } \\
\text { зования которого необходимы средства } \\
\text { вычислительной техники или иные спе- } \\
\text { циализированные устройства для воспро- } \\
\text { изведения текста, звука, изображения } \\
\text { (ссылка на ГОСТ Р 7.0.83-2013) }\end{array}$ & $\begin{array}{l}\text { ГОСТ Р 7.0.95-2015 СИБИД. } \\
\text { Электронные документы. Ос- } \\
\text { новные виды, выходные сведе- } \\
\text { ния, технологические характери- } \\
\text { стики (вводится в действие с } \\
\text { 01.07.2016 г.) }\end{array}$ \\
\hline $\begin{array}{l}\text { Электронная } \\
\text { коллекция }\end{array}$ & $\begin{array}{l}\text { Все документы в электронной форме, } \\
\text { сведения о которых включены в каталог } \\
\text { библиотеки, независимо от способа со- } \\
\text { здания и распространения, доступные } \\
\text { пользователям библиотеки или информа- } \\
\text { ционного центра }\end{array}$ & $\begin{array}{l}\text { ГОСТ Р 7.0.94-2015 СИБИД. } \\
\text { Комплектование библиотеки } \\
\text { документами. Термины и опре- } \\
\text { деления (вводится в действие с } \\
\text { 01.07.2016 г.) }\end{array}$ \\
\hline
\end{tabular}


Продолжение таблицы 3

\begin{tabular}{|c|c|c|}
\hline Вид ЭИР & Дефиниция & $\begin{array}{c}\text { Обозначение и наименование } \\
\text { стандарта }\end{array}$ \\
\hline $\begin{array}{l}\text { Электронное } \\
\text { издание }\end{array}$ & $\begin{array}{l}\text { Электронный документ (группа элек- } \\
\text { тронных документов), прошедший редак- } \\
\text { ционно-издательскую обработку, предна- } \\
\text { значенный для распространения в неиз- } \\
\text { менном виде, имеющий выходные сведе- } \\
\text { ния (ссылка на ГОСТ Р 7.0.83-2013) }\end{array}$ & $\begin{array}{l}\text { ГОСТ Р 7.0.94-2015 СИБИД. } \\
\text { Комплектование библиотеки } \\
\text { документами. Термины и опре- } \\
\text { деления (вводится в действие с } \\
01.07 .2016 \text { г.) }\end{array}$ \\
\hline $\begin{array}{l}\text { Электронная } \\
\text { книга }\end{array}$ & $\begin{array}{l}\text { Непериодическое электронное издание, } \\
\text { позволяющее производить по нему поиск, } \\
\text { представленное в режиме локального или } \\
\text { удаленного доступа. } \\
\text { Примечания: } \\
\text { 1. Издания, оцифрованные библиотекой, } \\
\text { относятся к электронным книгам. } \\
2 . \text { Электронные книги могут предостав- } \\
\text { ляться пользователям на мобильные } \\
\text { устройства для чтения, контент может } \\
\text { быть передан на персональные компью- } \\
\text { теры или устройства для чтения пользо- } \\
\text { вателя на ограниченный период времени }\end{array}$ & $\begin{array}{l}\text { ГОСТ Р 7.0.94-2015 СИБИД. } \\
\text { Комплектование библиотеки } \\
\text { документами. Термины и опре- } \\
\text { деления (вводится в действие с } \\
01.07 .2016 \text { г.) }\end{array}$ \\
\hline $\begin{array}{l}\text { Электронный } \\
\text { журнал }\end{array}$ & $\begin{array}{l}\text { Сериальное электронное издание, пред- } \\
\text { ставленное в режиме локального или } \\
\text { удалённого доступа }\end{array}$ & $\begin{array}{l}\text { ГОСТ Р 7.0.94-2015 СИБИД. } \\
\text { Комплектование библиотеки } \\
\text { документами. Термины и опре- } \\
\text { деления (вводится в действие с } \\
01.07 .2016 \text { г.) }\end{array}$ \\
\hline $\begin{array}{l}\text { Пакет } \\
\text { документов }\end{array}$ & $\begin{array}{l}\text { Массив документов, сформированный на } \\
\text { одной платформе по тематическому или } \\
\text { иному признаку из совокупности ресур- } \\
\text { сов, предлагаемых издателем или инфор- } \\
\text { мационным посредником }\end{array}$ & $\begin{array}{l}\text { ГОСТ Р 7.0.94-2015 СИБИД. } \\
\text { Комплектование библиотеки } \\
\text { документами. Термины и опре- } \\
\text { деления (вводится в действие с } \\
01.07 .2016 \text { г.) }\end{array}$ \\
\hline База данных & $\begin{array}{l}\text { Совокупность структурированных дан- } \\
\text { ных в электронной форме, с общим поль- } \\
\text { зовательским интерфейсом и программ- } \\
\text { ными средствами для доступа и обработ- } \\
\text { ки данных }\end{array}$ & $\begin{array}{l}\text { ГОСТ Р 7.0.94-2015 СИБИД. } \\
\text { Комплектование библиотеки } \\
\text { документами. Термины и опре- } \\
\text { деления (вводится в действие с } \\
01.07 .2016 \text { г.) }\end{array}$ \\
\hline $\begin{array}{l}\text { Электронная } \\
\text { библиотека }\end{array}$ & $\begin{array}{l}\text { Упорядоченное собрание разнородных } \\
\text { электронных документов (в том числе } \\
\text { книг), локализованных в информацион- } \\
\text { ной системе, снабжённых едиными сред- } \\
\text { ствами навигации и поиска, и доступных } \\
\text { через информационно-телекоммуника- } \\
\text { ционные сети }\end{array}$ & $\begin{array}{l}\text { ГОСТ Р 7.0.94-2015 СИБИД. } \\
\text { Комплектование библиотеки } \\
\text { документами. Термины и опре- } \\
\text { деления (вводится в действие с } \\
01.07 .2016 \text { г.) }\end{array}$ \\
\hline
\end{tabular}

Вновь вводимые в 2016 г. стандарты, на первый взгляд, вносят некоторые необходимые дополнения в существующую нормативную базу терминосистемы в сфере ЭИР через определения как родовых, так и видовых по- 
нятий. Но при этом даже в рамках одной и той же системы стандартов СИБИД ещё больше усложняется связь между ранее введёнными дефинициями термина информационные ресурсы (табл. 4) и термина электронные pecypcbl, который в ГОСТе Р 7.0.94-2015 СИБИД. «Комплектование библиотеки документами. Термины и определения» получает весьма расширенное толкование.

Таблица 4

Состав и характеристика дефиниций

термина «информационные ресурсы» в межгосударственных и национальных стандартах Российской Федерации

\begin{tabular}{|c|c|c|}
\hline Вид ЭИР & Дефиниция & $\begin{array}{c}\text { Обозначение и наименова- } \\
\text { ние стандарта }\end{array}$ \\
\hline $\begin{array}{l}\text { Информационные } \\
\text { ресурсы }\end{array}$ & $\begin{array}{l}\text { Совокупность данных, организован- } \\
\text { ных для эффективного получения } \\
\text { достоверной информации }\end{array}$ & $\begin{array}{l}\text { ГОСТ 7.0-99 СИБИД. Ин- } \\
\text { формационно-библиотечная } \\
\text { деятельность, библиография. } \\
\text { Термины и определения }\end{array}$ \\
\hline $\begin{array}{l}\text { Информационный } \\
\text { ресурс }\end{array}$ & $\begin{array}{l}\text { Любой объект, который можно иден- } \\
\text { тифицировать (такое же определение } \\
\text { в рекомендации Интернет RFC 2396). } \\
\text { Примечание. В данном определении } \\
\text { подразумеваются объекты, использу- } \\
\text { емые для хранения и передачи ин- } \\
\text { формации. }\end{array}$ & $\begin{array}{l}\text { ГОСТ Р 7.0.10-2010 СИБИД. } \\
\text { Набор элементов метаданных } \\
\text { «Дублинское ядро» }\end{array}$ \\
\hline $\begin{array}{l}\text { Информационные } \\
\text { ресурсы }\end{array}$ & $\begin{array}{l}\text { Совокупность данных, организован- } \\
\text { ных для эффективного получения } \\
\text { достоверной информации }\end{array}$ & $\begin{array}{l}\text { ГОСТ Р 7.0.94-2015 СИБИД. } \\
\text { Комплектование библиотеки } \\
\text { документами. Термины и } \\
\text { определения (вводится в } \\
\text { действие с } 01.07 .2016 \text { г.) }\end{array}$ \\
\hline
\end{tabular}

С другой стороны, нельзя не заметить и заложенной в ГОСТе Р 7.0.942015 СИБИД. «Комплектование библиотеки документами. Термины и определения» тенденции к выделению в качестве базовых терминов, характеризующих виды информационных ресурсов в условиях информационнокоммуникационных технологий, не только электронных, но и цифровых ресурсов, не рассматриваемых в качестве синонимов. При этом, исходя из дефиниций этих видов ресурсов, претендентом на участие в отношении «род - вид» вкупе с информационными ресурсами более всего выступают цифровые ресурсы.

Безусловно, весьма важно, что в контексте данного стандарта с позиций различных классификационных признаков устанавливаются виды электронных ресурсов. Однако не все классификационные признаки сформулированы чётко. Так, не определён признак, в соответствии с которым выде- 
лены: электронная коллекция, электронный образовательный ресурс, электронное издание, электронная книга, электронный журнал. Наряду с этим по форме организации в рамках данного стандарта различают следующие виды электронных ресурсов: пакет документов, база данных, библиографическая база данных, полнотекстовая база данных, реферативная база данных, фактографическая база данных, электронная библиотека.

Дифференцированно рассмотрены виды сетевых ресурсов как разновидности электронных ресурсов, доступных через информационнотелекоммуникационные сети, в числе которых - сетевые ресурсы локального (внутреннего) доступа и сетевые ресурсы удалённого (дистанционного) доступа, включая открытые интернет-ресурсы. Для этих видов электронных ресурсов в ГОСТе P 7.0.94-2015 даны определения, но способы их построения не вполне отвечают требованиям к построению терминосистемы, элементы которой связаны между собой отношениями «род - вид». Приведённый же в этом стандарте перечень видов электронных ресурсов не может претендовать на полноту и системность.

Недостаточная разработанность нормативной базы, регламентирующей создание и использование ЭИР, - один из важнейших факторов, определяющих и оправдывающих стремление библиотечно-информационных учреждений к идентификации создаваемых ЭИР с позиций «здравого смысла».

Вместе с тем, даже в тех случаях, когда нормативными документами чётко регламентированы виды ЭИР, на практике установленные каноны либо используются частично, либо не используются вообще, т.е. нормативные требования не соблюдаются. Это утверждение может быть проиллюстрировано на примере сопоставления видов баз данных, с одной стороны, установленных нормативными и рекомендательными документами, а с другой - выявленных в составе ЭИР на официальных сайтах ЦБ субъектов РФ (табл. 5). 
Соотношение нормативных и рекомендательных требований к видам баз данных, представленных на официальных сайтах ЦБ субъектов Российской Федерации

\begin{tabular}{|c|c|c|c|}
\hline \multirow[b]{2}{*}{$\begin{array}{c}\text { Наименование } \\
\text { вида БД }\end{array}$} & \multicolumn{3}{|c|}{ Виды баз данных в составе: } \\
\hline & $\begin{array}{l}\text { нормативно- } \\
\text { технических } \\
\text { документов }\end{array}$ & $\begin{array}{c}\text { нормативно- } \\
\text { рекомендательных } \\
\text { документов РБА }\end{array}$ & $\begin{array}{c}\text { рубрик сайтов ЦБ } \\
\text { субъектов РФ }\end{array}$ \\
\hline Документальная & + & & \\
\hline Библиографическая & + & + & + \\
\hline Реферативная & + & & + \\
\hline Полнотекстовая & + & + & + \\
\hline Фактографическая & + & + & \\
\hline Лексикографическая & + & & \\
\hline Объектографическая & + & & \\
\hline $\begin{array}{l}\text { База первичных } \\
\text { данных }\end{array}$ & + & & \\
\hline Текстовая & + & & \\
\hline Числовая & + & & \\
\hline Численно-текстовая & + & & \\
\hline Отсылочная & + & & \\
\hline Адресная & & + & \\
\hline $\begin{array}{l}\text { Официальных доку- } \\
\text { ментов }\end{array}$ & & + & \\
\hline Персональная & & + & \\
\hline Универсальная & & & + \\
\hline Тематическая & & + & \\
\hline Хроникальная & & + & \\
\hline Справочная & & & + \\
\hline $\begin{array}{l}\text { Справочно- } \\
\text { биографическая }\end{array}$ & & & + \\
\hline Гипертекстовая & + & & \\
\hline Иерархическая & + & & \\
\hline Реляционная & + & & \\
\hline Сетевая & + & & \\
\hline Распределённая & + & & \\
\hline Сводная & & & + \\
\hline Электронная & & & + \\
\hline
\end{tabular}

\section{Выводы и предложения}

Приведённые выше факты свидетельствуют: как в терминологической среде современной библиотечно-информационной практики, связанной с генерацией и использованием ЭИР, так и в нормативной базе, регулирующей эту деятельность, господствует субъективизм, следствия которого - 
неполнота, разнородность, несопоставимость, неопределённость (двусмысленность) информации, характеризующей ЭИР. Всё это, порождая серьёзные препятствия на пути конечных пользователей ЭИР, делает уязвимой саму идею продвижения информационных ресурсов библиотечноинформационных учреждений в открытое, доступное каждому члену общества информационное пространство.

Чтобы решить выявленные проблемы, с нашей точки зрения, следует упорядочить терминосистему в области ЭИР с позиций теоретических канонов системности терминологии и закреплённой стандартами терминологической политики [6], что предполагает:

- разработку многоаспектной классификации ЭИР с возможностью построения фасетной формулы каждого вида ЭИР;

- формирование унифицированной базовой терминологии, каждый элемент которой наделён полной совокупностью классификационных признаков;

- актуализацию нормативных документов, регламентирующих терминологию в сфере создания и эксплуатации ЭИР с позиций разработанной классификационной схемы;

- создание информационно-поисковых тезаурусов в сфере ЭИР;

- подготовку методических документов по представлению ЭИР различных видов в составе контента официальных сайтов ЦБ субъектов РФ.

Достигнутые результаты могут стать основой оптимизации современной библиотечно-информационной практики в области генерации и использования ЭИР только при условии их широкомасштабной трансляции в системе подготовки и повышения квалификации специалистов библиотечноинформационного профиля.

\section{СПИСОК ИСТОЧНИКОВ}

1. Канападзе Л. А. О понятиях «термин» и «терминология» / Л. А. Канападзе // Татаринов В. А. История отечественного терминоведения : в 3 т. Т. 2. Направления и методы терминологических исследований: Очерк и хрестоматия. - Москва : Московский лицей, 1995. - Книга 1. - С. 260-271.

Kanapadze L. A. O ponyatiyah «termin» $i$ «terminologiya» / L. A. Kanapadze // Tatarinov V. A. Istoriya otechestvennogo terminovedeniya : $v 3 t$. T. 2. Napravleniya i metody terminologicheskih issledovaniy: Ocherk i hrestomatiya. - Moskva : Moskovskiy litsey, 1995. - Kniga 1. - S. 260-271.

2. Лотте Д. С. Некоторые принципиальные вопросы отбора и построения научнотехнических терминов / Д. С. Лотте // Там же. - С. 112-134. 
Lotte D. S. Nekotorye printsipialnye voprosy otbora i postroeniya nauchno-tehnicheskih terminov / D. S. Lotte // Tam zhe. - S. 112-134.

3. ГОСТ 7.0-99. Система стандартов по библиотечному и издательскому делу. Информационно-библиотечная деятельность, библиография. Термины и определения [Текст] // Сб. осн. рос. стандартов по библ.-информ. деятельности / сост. Т. В. Захарчук. - Санкт-Петербург : Профессия, 2010. - С. 9-36.

GOST 7.0-99. Sistema standartov po bibliotechnomи i izdatelskomu delu. Informatsionnobibliotechnaya deyatelnost, bibliografiya. Terminy i opredeleniya [Tekst] // Sb. osn. ros. standartov po bibl.-inform. deyatelnosti/sost. T. V. Zaharchuk. - Sankt-Peterburg : Professiya, 2010. - S. 9-36.

4. ГОСТ Р ИСО 704-2010. Терминологическая работа. Принципы и методы [Электронный ресурс]. - Электрон. дан. - Москва : Стандартинформ, 2012. - 58 с. - (Федеральное агентство по техническому регулированию и метрологии: портал). - Режим доступа: http://protect.

gost.ru/document.aspx?control=7\&id=178586. - Загл. с экрана.

GOST R ISO 704-2010. Terminologicheskaya rabota. Printsipy i metody [Elektronnyy resurs]. Elektron. dan. - Moskva : Standartinform, 2012. - 58 s. - (Federalnoe agentstvo po tehnicheskomu regulirovaniyu i metrologii: portal).

5. ГОСТ 7.82-2001. СИБИД. Библиографическая запись. Библиографическое описание электронных ресурсов. Общие требования и правила составления [Текст] // Сб. осн. рос. стандартов по библ.-информ. деятельности / сост. Т. В. Захарчук. - Санкт-Петербург : Профессия, 2010. - C. 349-380.

GOST 7.82-2001. SIBID. Bibliograficheskaya zapis. Bibliograficheskoe opisanie elektronnyh resursov. Obshchie trebovaniya i pravila sostavleniya [Tekst] // Sb. osn. ros. standartov po bibl.inform. deyatelnosti/sost. T. V. Zaharchuk. - Sankt-Peterburg : Professiya, 2010. - S. 349-380.

6. ГОСТ Р ИСО 29383-2012. Терминологическая политика. Разработка и внедрение [Электронный ресурс]. - Электрон. дан. - Москва : Стандартинформ, 2014. - 20 с. - (Федеральное агентство по техническому регулированию и метрологии: портал). - Режим доступа: http://protect.gost.ru/document.aspx? control=7\&id=184458. - Загл. с экрана.

GOST R ISO 29383-2012. Terminologicheskaya politika. Razrabotka i vnedrenie [Elektronnyy resurs]. - Elektron. dan. - Moskva : Standartinform, 2014. - 20 s. - (Federalnoe agentstvo po tehnicheskomu regulirovaniyu i metrologii: portal).

Nadezhda Kolkova, Cand. Sci. (Pedagogy), Associate Professor, Professor of Computer-aided Information Processing Technology Chair, Kemerovo State Institute of Culture;

kolkovani@mail.ru

17 Voroshilova st., 650029, Kemerovo, Russia

Inna Skipor, Cand. Sci. (Pedagogy), Associate Professor, Head of Computer-aided Information Processing Technology Chair, Kemerovo State Institute of Culture;

skiporil@mail.ru

17 Voroshilova st., 650029, Kemerovo, Russia 